\title{
Evidence from stable-isotope labeling that catechol is an intermediate in salicylic acid catabolism in the flowers of Silene latifolia (white campion)
}

\author{
Kristen Van Gelder ${ }^{1} \cdot$ Taylor Forrester $^{1} \cdot$ Tariq A. Akhtar $^{1} \mathbb{B}$
}

Received: 24 March 2020 / Accepted: 4 June 2020 / Published online: 8 June 2020

(c) The Author(s) 2020

\begin{abstract}
Main conclusion A stable isotope-assisted mass spectrometry-based platform was utilized to demonstrate that the plant hormone, salicylic acid, is catabolized to catechol, a widespread secondary plant compound.
\end{abstract}

\begin{abstract}
The phytohormone salicylic acid (SA) plays a central role in the overall plant defense program, as well as various other aspects of plant growth and development. Although the biosynthetic steps toward SA are well documented, how SA is catabolized in plants remains poorly understood. Accordingly, in this study a series of stable isotope feeding experiments were performed with Silene latifolia (white campion) to explore possible routes of SA breakdown. S. latifolia flowers that were fed a solution of $\left[{ }^{2} \mathrm{H}_{6}\right]$-salicylic acid emitted the volatile and potent pollinator attractant, 1,2-dimethoxybenzene (veratrole), which contained the benzene ring-bound deuterium atoms. Extracts from these S. latifolia flowers revealed labeled catechol as a possible intermediate. After feeding flowers with $\left[{ }^{2} \mathrm{H}_{6}\right]$-catechol, the stable isotope was recovered in veratrole as well as its precursor, guaiacol. Addition of a trapping pool of guaiacol in combination with $\left[{ }^{2} \mathrm{H}_{6}\right]$-salicylic acid resulted in the accumulation of the label into catechol. Finally, we provide evidence for catechol $O$-methyltransferase enzyme activity in a population of $S$. latifolia that synthesizes veratrole from guaiacol. This activity was absent in non-veratrole emitting flowers. Taken together, these results imply the conversion of salicylic acid to veratrole in the following reaction sequence: salicylic acid $>$ catechol $>$ guaiacol $>$ veratrole. This catabolic pathway for SA may also be embedded in other lineages of the plant kingdom, particularly those species which are known to accumulate catechol.
\end{abstract}

Keywords Catabolism $\cdot$ Catechol $\cdot O$-methyltransferase $\cdot$ Phytohormone $\cdot$ Salicylic acid

$\begin{array}{ll}\text { Abbreviations } \\ \text { CA-d6 } & {\left[{ }^{2} \mathrm{H}_{6}\right]-\text { Catechol }} \\ \text { CTOMT } & \text { Catechol } O \text {-methyltransferase } \\ \text { MeSA } & \text { Methyl salicylate } \\ \text { SA } & \text { Salicylic acid } \\ \text { SA-d6 } & {\left[{ }^{2} \mathrm{H}_{6}\right] \text {-Salicylic acid }}\end{array}$

Communicated by Dorothea Bartels.

Electronic supplementary material The online version of this article (https://doi.org/10.1007/s00425-020-03410-5) contains supplementary material, which is available to authorized users.

Tariq A. Akhtar

takhtar@uoguelph.ca

1 Department of Molecular and Cellular Biology, University of Guelph, Guelph, ON N1G 2W1, Canada

\section{Introduction}

The plant hormone, salicylic acid (SA), plays a central role in the overall plant defense response against pathogens and mediates several other aspects of plant growth and development (Vlot et al. 2009; Dempsey et al. 2011; Klessig et al. 2018; Zhang and Li 2019). As observed with other plant hormones, the level of SA within tissues is known to be tightly regulated to ensure the proper function of defense and developmental programs (Zhang et al. 2010; Dempsey et al. 2011; Seguel et al. 2018). With over a half century of research into SA metabolism, the biosynthetic steps toward SA have been almost fully elucidated (Rekhter et al. 2019; Torrens-Spence et al. 2019). However, the catabolism of this essential plant hormone remains somewhat of an enigma.

In plants, there are two pathways that operate in SA biosynthesis: the isochorismate (IC) pathway in the plastid and the phenylalanine ammonia lyase (PAL) pathway within the 
cytosol (Dempsey et al. 2011). Depending on the particular species, one or the other pathway will typically predominate (Chen et al. 2009). In addition, each SA biosynthetic pathway can be preferentially triggered by specific abiotic and/or biotic factors (Gaffney et al. 1993; Delaney et al. 1994; Rivas-San Vicente and Plasencia 2011). While the precursors and intermediates of each pathway have been well defined through a combination of genetic and isotopeassisted labeling approaches in several plants (Yalpani et al. 1993; Ribnicky et al. 1998; Jarvis et al. 2000; Chong et al. 2001; Wildermuth 2006; Strawn et al. 2007), the genes encoding the final enzymatic steps for SA biosynthesis via the IC pathway were only recently identified in Arabidopsis (Rekhter et al. 2019; Torrens-Spence et al. 2019). The multi-drug and toxin extrusion transporter enhanced disease susceptibility5 (EDS5) first transports IC out of the plastid (Nawrath et al. 2002; Serrano et al. 2013), where it is conjugated to glutamate by the cytosolic amidotransferase, avrPphB susceptibile3 (PBS3), to isochorismoyl-glutamate (Jagadeeswaran et al. 2007; Lee et al. 2007; Nobuta et al. 2007; Rekhter et al. 2019). At present, it is believed that this intermediate is finally converted into SA via a combination of spontaneous non-enzymatic decomposition and the isochorismoyl-glutamate pyruvoyl-glutamate lyase activity of the enhanced Pseudomonas susceptibility (EPS1) protein (Zheng et al. 2009; Torrens-Spence et al. 2019). The genetic basis for SA biosynthesis via the PAL pathway is less well understood; however, isotopic labeling studies have demonstrated that it is derived from phenylalanine through transcinnamic acid and benzoic acid intermediates (El-Basyouni et al. 1964; Wildermuth et al. 2001; Chen et al. 2009; Dempsey et al. 2011).

Following its synthesis, the active pool of SA may be reduced via a series of modifications to its hydroxybenzoic acid backbone that form inactive storage forms of the hormone (Fig. 1). Glycosylation of SA to SA $2-\mathrm{O}-\beta$-D-glucose (SAG) or SA glucose ester (SGE) represent vacuolar storage pools (Dean et al. 2005; Dean and Delaney 2008; Song et al. 2008). Additional inactive forms of SA include 2,3- and 2,5-dihydroxybenzoic acid (2,3- and 2,5-DHBA) which are synthesized by salicylic acid 3-hydroxylase ( $\mathrm{S} 3 \mathrm{H})$ and salicylic acid 5-hydroxylase (S5H/DMR6), respectively (Fig. 1; Zhang et al. 2013, 2017). 2,3- and 2,5-DHBA mainly exist as glycosides, either as O- $\beta$-D-glucosides or O- $\beta$-D-xylosides (Bartsch et al. 2010; Zhang et al. 2013), and are thought to be translocated to the vacuole for storage as well. SA can also be liberated from SAG by SA $\beta$-glucosidase (Seo et al. 1995), which 'fine-tunes' the bioavailability of SA. Finally, in both leaves and more commonly in floral organs, a methyl group from S-adenosine-L-methionine (SAM) can be added to the carboxyl group of SA by specific SA methyltransferases (Ross et al. 1999; Chen et al. 2003) to form methyl salicylate (MeSA). MeSA is a volatile compound emitted from flowers to attract pollinators. It has also been suggested

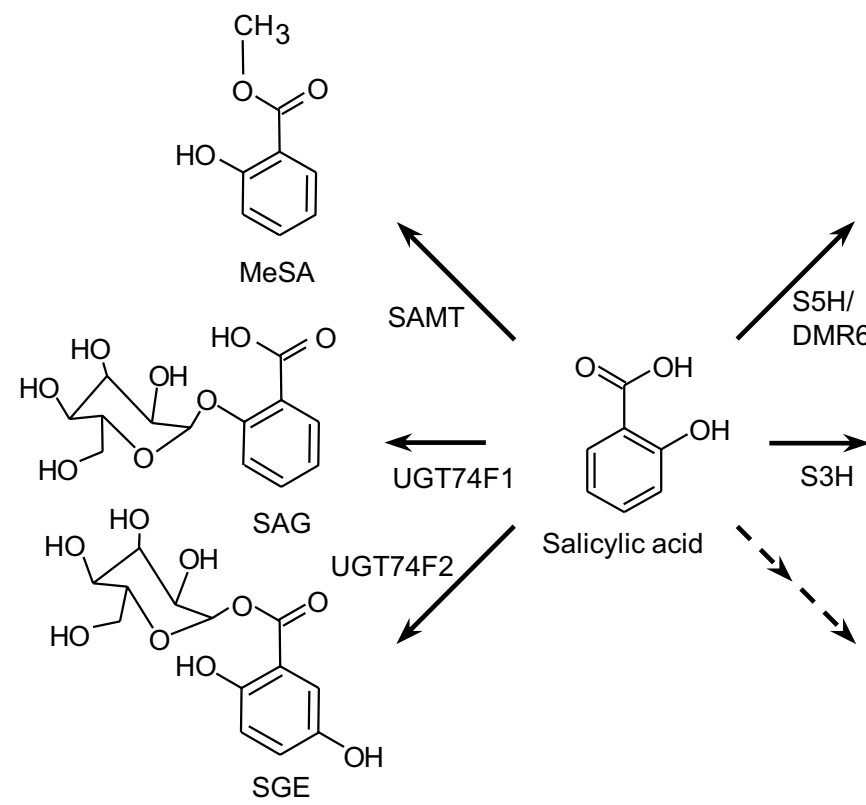

Fig. 1 Routes of salicylic acid metabolism in plants. Dashed arrows indicate enzymatic steps that remain uncharacterized. Solid arrows indicate reactions for which plant enzymes have been identified. CTOMT, catechol $o$-methyltransferase; DHBA, dihydroxybenzoic acid; DHBX, dihydroxybenzoic glycoside; DMR6, Downy Mildew Resistant 6; GOMT, guaiacol o-methyltransferase; MeSA, methyl

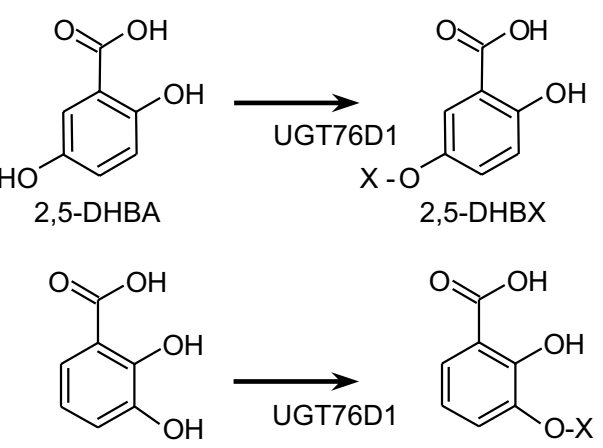

2,3-DHBA 2,3-DHBX

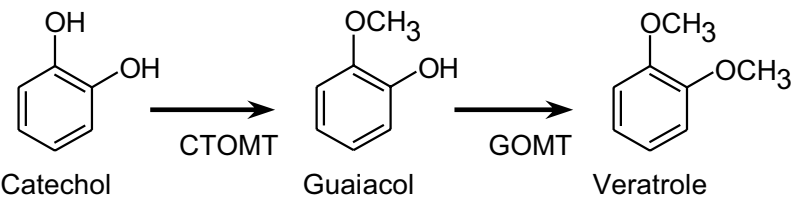

salicylate; S3H, salicylic acid 3-hydroxylase; S5H, salicylic acid 5-hydroxylase; SAMT, salicylic acid methyltransferase; SAG; salicylic acid glycoside; SGE, salicylic acid glucose ester; UGT, UDPglucosyltransferase; X-glucose or xylose. UGT74F2 also catalyzes the formation of SAG and is commonly referred to as salicylic acid gluosyltransferase1 (SGT1) 
that MeSA acts as a long-distance signal of SA-mediated defense programs (Chen et al. 2003; Park et al. 2008); however, this phenomenon has yet to be conclusively resolved (Attaran et al. 2009). No other routes for SA disposal or repurposing have been reported in planta.

Certain species of bacteria and fungi that can degrade aromatic hydrocarbons are known to convert SA into basic Krebs cycle intermediates (Ambrose et al. 2015). As a first step in this catabolic pathway, SA is oxidatively decarboxylated-the prototypical salicylate hydroxylase from Pseudomonas putida, $\mathrm{NahG}$, catalyzes the hydroxylation and simultaneous decarboxylation of SA into catechol (Yamamoto et al. 1965). Transgenic plants that overexpress NahG are known to have lower levels of SA, accumulate high amounts of catechol, and are impaired in various defense responses against fungal, bacterial and viral pathogens (Gaffney et al. 1993; Delaney et al. 1994; van Wees and Glazebrook 2003). However, there have been no orthologs of $\mathrm{NahG}$ that have been identified in plants. It is noteworthy that several plant species are known to accumulate catechol (Towers et al. 1966; Morse et al. 2007; Mageroy et al. 2012), thus tempting speculation that analogous SA decarboxylative enzyme activity may also be present in such plants.

In this study, we explored SA catabolism using a stable isotope-assisted mass spectrometry platform that was recently developed to follow the fate of labeled SA through the flowers of the dioecious angiosperm, Silene latifolia (white campion). Similar to the aroma of many plants, the scent emitted by S. latifolia flowers comprises a mixture of volatile isoprenoids, phenylpropanoids and fatty-acid derivatives (Pichersky and Gershenzon 2002; Dötterl et al. 2005; Knudsen et al. 2006). Of particular note is 1,2-dimethoxybenzene (veratrole), a potent pollinator attractant which can account for up to $40 \%$ of the total floral bouquet of S. latifolia and which labeling studies previously indicated may in fact be derived from SA, through guaiacol, another volatile pollinator attractant (Dötterl et al. 2005, 2006; Akhtar and Pichersky 2013). Accordingly, we utilized this S. latifolia system to probe for possible intermediates in SA catabolism using a combination of stable isotope labeling, isotope trapping, and enzymatic assay approaches. Evidence is provided for a catabolic pathway for SA that involves catechol as a central intermediate.

\section{Materials and methods}

\section{Chemicals and reagents}

Deuterium-labeled 1,2-dihydroxybenzene-d6 (98\% atom deuterium) and 2-hydroxybenzoic acid-d6 (98.8\% atom deuterium) were from CDN isotopes (Pointe-Claire, QC, Canada). S-[Methyl- $\left.{ }^{14} \mathrm{C}\right]$ adenosyl-L-methionine
(2.146 GBq) was from PerkinElmer. Catechol, guaiacol, salicylic acid, 1,2-dihdroxybenzoic acid, and veratrole were obtained from Sigma-Aldrich (Oakville, ON, Canada). All other materials were obtained from SigmaAldrich or Fisher Scientific.

\section{Plant material and growth conditions}

Silene latifolia seeds were obtained from a wild population originating from Blacksburg, VA, USA. Plants were grown in potting soil supplemented with Osmocote (Scotts) and maintained in growth chambers under a $16 \mathrm{~h}$ photoperiod $\left(150 \mu \mathrm{mol} \mathrm{m} \mathrm{m}^{-2} \mathrm{~s}^{-1}\right.$; mixed cool white and incandescent bulbs). Temperature was maintained at $23{ }^{\circ} \mathrm{C}$ during the light period and $18{ }^{\circ} \mathrm{C}$ during darkness. Relative humidity was kept at $60 \%$. The plant material was identified and authenticated by Dr. Carole Ann Lacroix and a voucher specimen (No. 102507) was deposited at the Ontario Agricultural College Herbarium in Guelph, Ontario, Canada.

\section{Substrate feeding and volatile analysis}

Fully developed male or female $S$. latifolia flowers were excised at the base of the calyx, placed in a $10 \mathrm{~mL}$ solution containing substrate and volatiles were collected by solidphase microextraction (SPME) according to the method described by Akhtar and Pichersky (2013) with minor modifications. All substrates were supplied at a concentration of $10 \mathrm{mM}$ and flowers were left in the solution under light for $1 \mathrm{~h}$. The setup was then transferred to the dark for $1.5 \mathrm{~h}$, followed by $20 \mathrm{~min}$ of volatile collection. Volatiles were desorbed from the SPME fiber and analyzed with an Agilent 7890A gas chromatography system coupled to an Agilent 5975C triple axis mass selective detector equipped with a Bruker BR-SWAX column (30-m length, $0.25 \mathrm{~mm}$ I.D., $0.50 \mu \mathrm{m}$ phase thickness) using the following temperature program: $44{ }^{\circ} \mathrm{C}$ for $3.5 \mathrm{~min}$, ramp of $5{ }^{\circ} \mathrm{C} \mathrm{min}{ }^{-1}$ to $200{ }^{\circ} \mathrm{C}$, ramp of $70{ }^{\circ} \mathrm{C} \mathrm{min}^{-1}$ to $250{ }^{\circ} \mathrm{C}$, and hold for $1 \mathrm{~min}$. The desorption was performed within the injector in splitless mode at $280{ }^{\circ} \mathrm{C}$. Helium was used as the carrier gas at a rate of $1 \mathrm{~mL} \mathrm{~min}^{-1}$. The mass spectrometer was scanned from 50 to $550 \mathrm{~m} / \mathrm{z}$ at a cycle of $1 \mathrm{~s}$. Electron impact ionization at $70 \mathrm{eV}$ was used with the source at $200{ }^{\circ} \mathrm{C}$, while the transfer line was kept at $250{ }^{\circ} \mathrm{C}$. The data were acquired after a 3 min solvent delay in positive ion mode and the assignment of each chromatographic peak was determined by searching the GC-MS mass spectral library (US National Institute of Standards and Technology, NIST 2011). Once the peaks were tentatively identified with the mass spectral library, the authentic standards were injected for positive identification in comparison with retention times and mass spectra. 


\section{Catechol extraction and analysis by GC-MS/MS}

Silene latifolia flowers ( $200 \mathrm{mg}$ ) were flash frozen in liquid nitrogen and ground to a fine powder with a mortar and pestle. Catechol was extracted by adding five volumes of methanol: $\mathrm{H}_{2} \mathrm{O}(7: 3, v / v)$ to the tissue powder, followed by rigorous shaking for $1 \mathrm{~min}$. After incubation for $24 \mathrm{~h}$ at $4{ }^{\circ} \mathrm{C}$, extracts were clarified by centrifugation at 12,000 $\mathrm{g}$ for $5 \mathrm{~min}$ and the supernatant was dried in vacuo. Dried samples were silylated with $400 \mu \mathrm{L}$ of N-methyl-N-(trimethylsilyl)trifluoroacetamide (MSTFA) at $70{ }^{\circ} \mathrm{C}$ for $2 \mathrm{~h}$ and immediately analyzed with a Scion TQ GC-MS/MS (Bruker Daltonics Inc.) equipped with an Agilent DB-5MS column (30-m length, $0.25 \mathrm{~mm}$ I.D., $0.25 \mu \mathrm{m}$ film thickness) using the following program: $80{ }^{\circ} \mathrm{C}$ for $2 \mathrm{~min}$, ramp of $10^{\circ} \mathrm{C} \mathrm{min} \mathrm{m}^{-1}$ to $230{ }^{\circ} \mathrm{C}$, ramp of $40{ }^{\circ} \mathrm{C} \min ^{-1}$ to $310^{\circ} \mathrm{C}$, and hold for $5 \mathrm{~min}$. The inlet temperature was $280{ }^{\circ} \mathrm{C}$ and sample injection was performed in splitless mode. Helium was used as the carrier gas at a rate of $1 \mathrm{~mL} \mathrm{~min}^{-1}$. Mass spectral data were acquired in electron impact (EI)-positive ionization mode at $70 \mathrm{eV}$ with selected reaction monitoring (SRM) using $2 \mathrm{mT}$ Torr collision pressure and $30 \mathrm{eV}$ for precursor ion fragmentation mode. The precursor and product ion transitions for catechol and deuteriumlabeled catechol were established using authentic standards and were 254 to $>73 \mathrm{~m} / z$ and 258 to $>73 \mathrm{~m} / z$, respectively.

\section{Protein extraction and CTOMT enzyme assays}

Flash-frozen plant material was ground to a fine powder and protein was extracted in Buffer A [100 mM Tris- $\mathrm{HCl}, \mathrm{pH} 7.5$, $5 \mathrm{mM} \mathrm{MgCl} 2,10 \mathrm{mM} \beta$-mercaptoethanol and $10 \%$ glycerol $(w / v)]$. Soluble crude extracts were centrifuged at $4{ }^{\circ} \mathrm{C}$ and the supernatant was desalted on PD-10 columns (GE Healthcare) or using Sephadex G25 minicolumns (Helmerhorst and Stokes 1980) equilibrated in Buffer A. Protein concentration was determined by the method of Bradford (1976). Enzyme assays were conducted at room temperature and contained $\sim 15 \mu \mathrm{g}$ of desalted crude extract, $1 \mathrm{mM}$ catechol, and $5 \mu \mathrm{M} \mathrm{S}$-[methyl${ }^{14} \mathrm{C}$ ] adenosyl-L-methionine $(2.146 \mathrm{GBq})$ in a final volume of $50 \mu \mathrm{L}$ containing Buffer A. Reaction products were extracted with $200 \mu \mathrm{L}$ of ethyl acetate and quantified using a scintillation counter (model LS 6500; Beckman). To identify reaction products, enzyme assays were conducted as described above with $200 \mu \mathrm{M}$ S-adenosyl-L-methionine and analyzed by GC-MS according to the method used for volatile analysis.

\section{Results}

\section{Stable isotope feeding points to catechol as a precursor in veratrole biosynthesis}

S. latifolia is a dioecious angiosperm that emits an array of volatile compounds from both its male and female flowers (Jürgens et al. 2002; Dötterl et al. 2005). Among these emitted volatiles is the potent pollinator attractant known as veratrole (1,2-dimethoxybenzene), which is believed to be derived from salicylic acid based on stable isotope labeling studies (Akhtar and Pichersky 2013). Indeed, we confirmed that $S$. latifolia flowers that were fed a solution of deuterium-labeled $\left[{ }^{2} \mathrm{H}_{6}\right]$-salicylic acid (SA-d6) emit a portion of veratrole molecules with a 4-Da shift in the mass of the parent ion and its associated mass spectral fragments (Fig. 2), as originally demonstrated by Akhtar and Pichersky (2013). It should be noted that only four benzene ring-bound deuterium atoms remain on the SA-d6 label in planta, as the carboxyl and hydroxyl group readily ionize and undergo $\mathrm{H} / \mathrm{D}$ back exchange when in solution, respectively. A similar 4-Da shift in the parent ions and associated mass spectral fragments of guaiacol and MeSA was also observed in the floral bouquet from these flowers, as previously demonstrated by Akhtar and Pichersky (2013; Fig. 2). While it was expected that the emitted MeSA would capture the fed label since SA is its immediate precursor, the incorporation of the SA-derived label into guaiacol was intriguing for two reasons. First, guaiacol is the immediate precursor to veratrole in plants that synthesize these two compounds (Gupta et al. 2012; Koeduka et al. 2016). Second, guaiacol is known to be derived from catechol in certain plants (Mageroy et al. 2012). While the origin of catechol in plants remains unclear, these labeling studies imply the involvement of catechol as a precursor to veratrole biosynthesis in the flowers of S. latifolia. Therefore, we formally tested this possibility by feeding flowers a solution of $\left[{ }^{2} \mathrm{H}_{6}\right]$-catechol (CA-d6) and then subsequently monitored the incorporation of the label into the volatiles that were released. A portion of both guaiacol and veratrole molecules that were emitted from these flowers exhibited a 4-Da shift in the mass of their parent ions and associated mass spectral fragments; no such shift in the mass of emitted MeSA from these flowers was observed (Fig. 2). Taken together, these labeling studies reveal that the benzene ring of veratrole and its immediate precursor, guaiacol, can be derived from either SA and/or catechol. These results, however, do not clarify where catechol fits, if at all, into the SA catabolic network.

\section{Isotope trapping implicates catechol as an intermediate in SA catabolism}

To clarify how the label from SA-d6 into veratrole proceeds and how catechol might partake in this pathway, a series of 


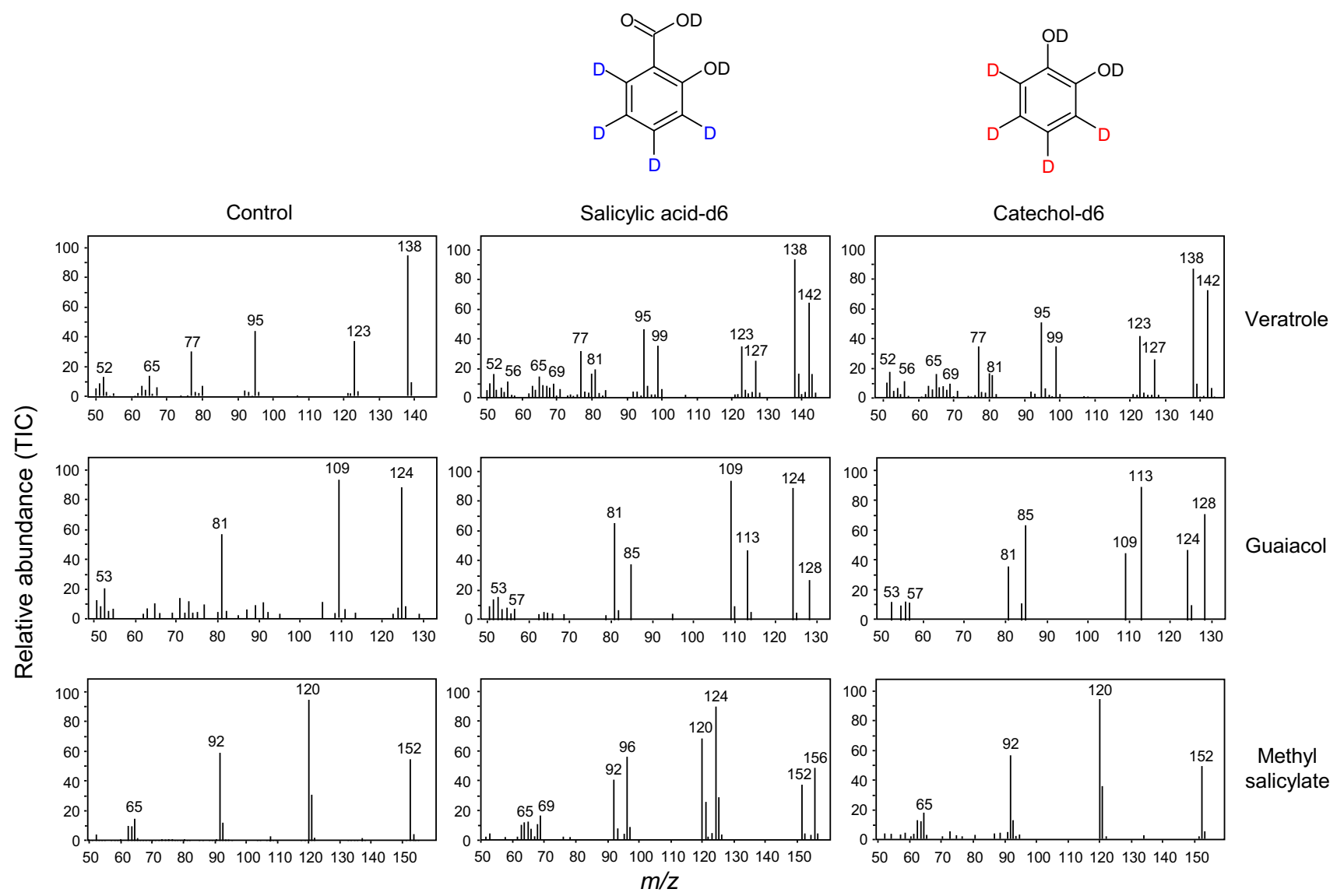

Fig. 2 Stable isotope incorporation into $S$. latifolia volatiles. Detached flowers were fed water (control), solutions containing $10 \mathrm{mM}\left[{ }^{2} \mathrm{H}_{6}\right]$-catechol (CA-d6), or $10 \mathrm{mM}\left[{ }^{2} \mathrm{H}_{6}\right]$-salicylic acid (SAd6) for $1.5 \mathrm{~h}$ in the dark and volatiles were then analyzed by GC-MS. The mass spectra (TIC) of veratrole, guaiacol, and methyl salicylate

isotope trapping experiments were next performed. First, S. latifolia flowers were placed in a solution of SA-d6 with or without unlabeled catechol and the incorporation of the stable isotope label into both guaiacol and veratrole were determined. On average, approximately $45 \%$ of these emitted volatiles incorporated the deuterium label when fed SA-d6 alone; however, when unlabeled catechol was included in these feeding studies, the incorporation of the label into guaiacol and veratrole fell below 10\% (Fig. 3). Together, these results suggest that catechol can trap the SA-d6 label from being incorporated into veratrole and potentially operate downstream from SA en route to the biosynthesis of veratrole in S. latifolia flowers.

To demonstrate that the label derived from SA-d6 could be converted into catechol, in planta, a tandem mass spectrometry method was developed to monitor labeled and unlabeled catechol in extracts from $S$. latifolia flowers that were accordingly fed the labeled substrate. Following derivatization of methanolic extracts from these flowers (via silylation), selected reaction monitoring was able to emitted from the flowers are shown. Note the 4 mass unit shift of the parent ions and mass spectral fragments of veratrole $(\mathrm{m} / \mathrm{z}=138)$, guaiacol $(\mathrm{m} / \mathrm{z}=124)$, and methyl salicylate $(\mathrm{m} / \mathrm{z}=152)$ upon feeding with CA-d6 or SA-d6. Mass spectra are representative of a minimum of six feeding experiments

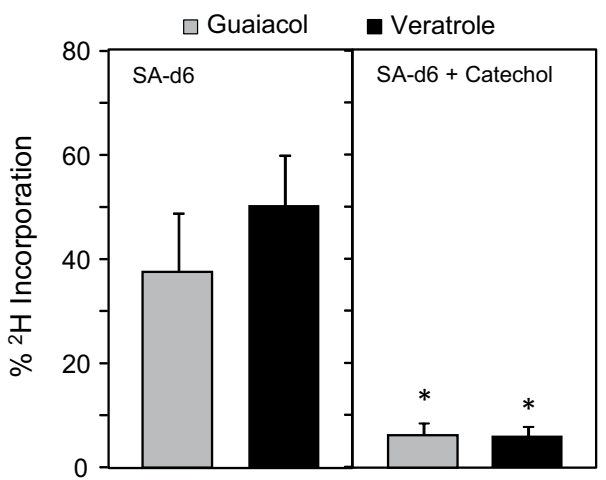

Fig. 3 Stable isotope trapping of $\left[{ }^{2} \mathrm{H}_{6}\right]$-salicylic acid. Detached flowers were placed in solution containing $10 \mathrm{mM}$ deuterium-labeled salicylic acid (SA-d6), with or without $10 \mathrm{mM}$ unlabeled catechol. Volatiles were collected by solid-phase microextraction and analyzed by GC-MS. The incorporation of the stable isotope into the parent ion of guaiacol and veratrole is expressed as a percentage of the total for each compound. Data are the means \pm SD of four separate feeding experiments and asterisks indicate a significant difference $(P<0.05)$ of isotope incorporation into guaiacol and veratrole between the two experiments 
unambiguously detect mass transitions for labeled catechol (258-73) and unlabeled catechol (254-73) in these samples according to their comparison with authentically processed standards (Fig. 4, Fig. S1). In flowers that were fed unlabeled SA, only unlabeled catechol could be detected; however in extracts from those flowers that were fed SA-d6, both labeled and unlabeled catechol were present (Fig. 4). In the context of SA catabolism, these labeling studies provide evidence for the conversion of SA into catechol.

Next, a dose-dependent isotope trapping experiment was performed by providing the SA-d6 label to flowers along with increasing amounts of unlabeled guaiacol. Three

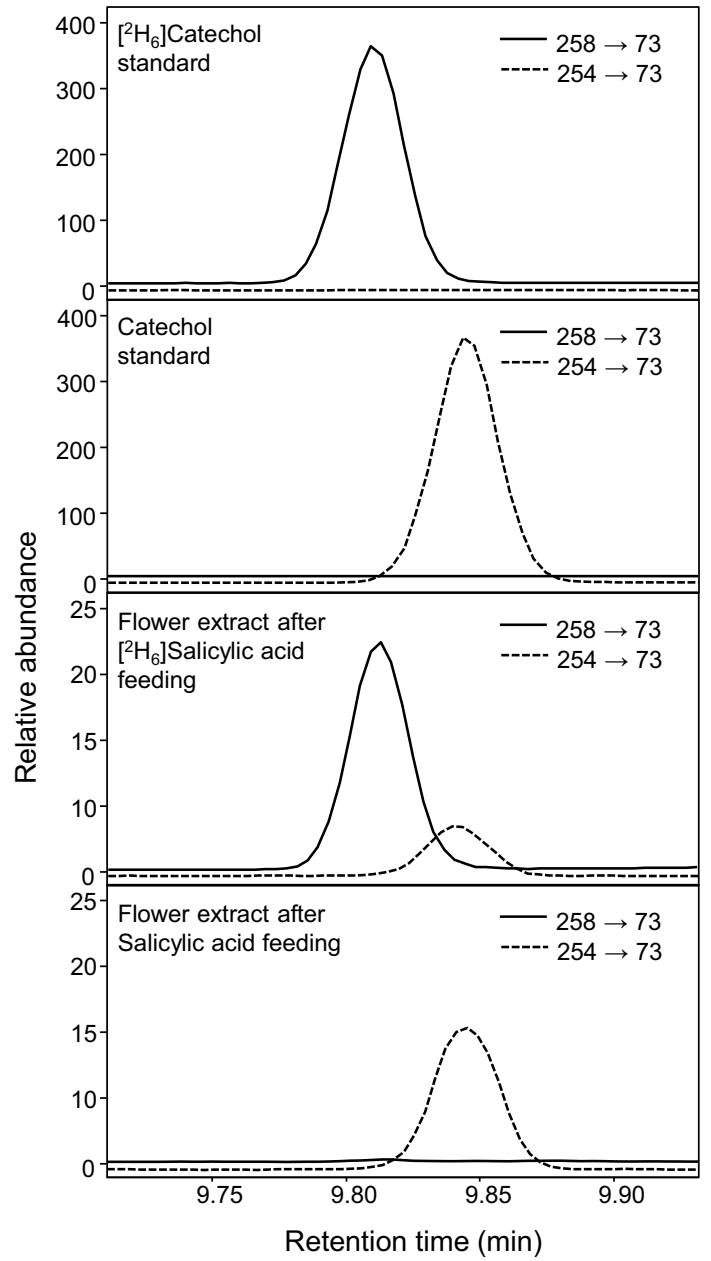

Fig. 4 Evidence for the in planta conversion of salicylic acid to catechol. Soluble extracts from $S$. latifolia flowers that were fed a solution of deuterium-labeled $\left[{ }^{2} \mathrm{H}_{6}\right]$-salicylic acid or unlabeled salicylic acid were analyzed for the presence of deuterium-labeled catechol and catechol. A GC-MS/MS method with selected reaction monitoring was developed to monitor the mass transitions of 258-73 and 254-73 for labeled and unlabeled catechol, respectively. The top two panels illustrate the detection of authentic standards of labeled catechol and unlabeled catechol using this method. The bottom two panels illustrate the analysis of extracts from flower tissue that were fed the indicated compounds general trends were observed in these flowers: first, the proportion of emitted veratrole molecules that contained the label steadily decreased as the dose of unlabeled guaiacol was increased; second, and conversely, the internal pool of labeled catechol increased in accordance with the amount of unlabeled guaiacol that was co-administered with the SA-d6 label to these flowers; third, a steady increase in the proportion of emitted MeSA containing the label was observed with increasing amounts of the unlabeled guaiacol that was administered (Table 1). To corroborate these observations, the SA-d6 label was then replaced with a solution of CA-d6 along with increasing amounts of unlabeled guaiacol and the incorporation of the isotope was monitored accordingly. In these flowers, the internal pool of labeled catechol progressively increased while the proportion of emitted veratrole containing the label steadily decreased with increasing doses of unlabeled guaiacol, respectively (Table 2). To summarize, the results of these labeling studies reveal the following: (1) the in vivo transfer of the SA-d6 label into veratrole can be inhibited by co-administration of either catechol or guaiacol, and that (2) the in vivo transfer of the CA-d6 label into veratrole can also be inhibited by guaiacol. Taken together, a linear catabolic pathway for SA is therefore implied, which first involves the conversion of SA into catechol followed by its conversion into guaiacol and then ultimately to veratrole (Fig. 1).

\section{Catechol 0-methyltransferase activity in the flowers of S. Iatifolia}

Genetic and biochemical evidence for a guaiacol- $O$-methyltransferase (GOMT) in $S$. latifolia that catalyzes the conversion of guaiacol to veratrole lends support to an

Table 1 Guaiacol as a trapping pool for $\left[{ }^{2} \mathrm{H}_{6}\right]$ salicylic acid catabolism

\begin{tabular}{|c|c|c|c|}
\hline \multirow{2}{*}{$\begin{array}{l}\text { Unlabeled } \\
\text { Guaiacol } \\
\text { Dose }\end{array}$} & \multicolumn{3}{|l|}{$\left[{ }^{2} \mathrm{H}\right]$ Distribution } \\
\hline & Methyl salicylate & Veratrole & $\begin{array}{l}\text { Internal }\left[{ }^{2} \mathrm{H}_{6}\right] \\
\text { Catechol }\end{array}$ \\
\hline $\mathrm{mM}$ & $\%$ parent ion & $\%$ parent ion & $n g g^{-1}$ fresh wt \\
\hline 0 & $43.20 \pm 2.17$ & $38.5 \pm 6.06$ & $0.46 \pm 0.3$ \\
\hline 1 & $47.75 \pm 8.84$ & $28.40 \pm 2.94$ & $0.55 \pm 0.19$ \\
\hline 2 & $50.40 \pm 2.06$ & $12.50 \pm 0.69$ & $0.90 \pm 0.37$ \\
\hline 5 & $66.25 \pm 2.86$ & $5.37 \pm 2.02$ & $1.42 \pm 0.63$ \\
\hline
\end{tabular}

Detached flowers were fed a solution containing $10 \mathrm{mM}$ $\left[{ }^{2} \mathrm{H}_{6}\right]$-salicylic acid in combination with the indicated concentrations of guaiacol. The conversion of $\left[{ }^{2} \mathrm{H}_{6}\right]$-salicylic acid into methyl salicylate and veratrole was determined by the incorporation of ${ }^{2} \mathrm{H}$ into their respective parent ions of methyl salicylate and veratrole were determined by GC-MS and is expressed as a percentage of the total. Data are the mean values \pm SE from five independent feeding experiments 
Table 2 Guaiacol prevents $\left[{ }^{2} \mathrm{H}_{6}\right]$-catechol incorporation into veratrole

\begin{tabular}{lll}
\hline $\begin{array}{l}\text { Unlabeled Guaiacol } \\
\text { dose }\end{array}$ & $\begin{array}{l}{\left[{ }^{2} \mathrm{H}\right] \text { Incorporation in }} \\
\text { veratrole }\end{array}$ & Internal $\left[{ }^{2} \mathrm{H}_{6}\right]$ catechol \\
\hline $\mathrm{mM}$ & $\%$ parent ion & $\mathrm{ng} \mathrm{g}^{-1}$ fresh wt \\
0 & $45.13 \pm 6.71$ & $4.54 \pm 2.84$ \\
1 & $22.25 \pm 3.41$ & $12.73 \pm 5.99$ \\
2 & $12.97 \pm 2.37^{*}$ & $10.65 \pm 4.42$ \\
5 & $9.33 \pm 0.41^{*}$ & $22.85 \pm 11.86$ \\
\hline
\end{tabular}

Detached flowers were fed a solution containing $10 \mathrm{mM}$ $\left[{ }^{2} \mathrm{H}_{6}\right]$-catechol together with the indicated doses of guaiacol for a period of $2 \mathrm{~h}$. Following the feeding period, volatiles emitted by the detached flowers were collected and the amount of ${ }^{2} \mathrm{H}$ incorporated into the parent ion of veratrole was quantified by GC-MS and expressed as the percentage of the total. The internal amount of $\left[{ }^{2} \mathrm{H}_{6}\right]$-catechol in the same detached flowers was then extracted and quantified by GC-MS/MS and expressed on a fresh weight basis. Data are the mean values \pm SE from six independent feeding experiments. Asterisks indicate a significant difference $(P<0.05)$ compared to flowers that were not provided guaiacol

SA catabolic pathway in this plant species (Akhtar and Pichersky 2013; Gupta et al. 2012). To further explore this line of inquiry, we next surveyed $S$. latifolia for catechol$O$-methyltransferase (CTOMT) enzyme activity, which would be responsible for converting catechol into guaiacol and would theoretically represent the penultimate step in SA catabolism, according to the previously described in planta labeling studies. As a precedent for this analysis, a CTOMT was previously established to be responsible for guaiacol biosynthesis in tomato fruit, where it serves as an important factor in governing aroma, flavor, and fruit quality (Mageroy et al. 2012). We first assayed for CTOMT activity in S. latifolia flowers by providing de-salted protein extracts with catechol and the universal methyl donor, $S$-adenosyl-L-methionine (SAM). The in vitro reaction products from these assays were then analyzed by GC-MS and shown to include a compound whose retention time and mass spectra matched that of an authentic guaiacol standard; assays without SAM were devoid of this enzymatic product and we found no evidence for nonenzymatic methylation of catechol (Fig. 5a; Fig. S2). We next analyzed CTOMT enzyme activity in a variety of $S$. latifolia tissues-male and female flowers were accordingly dissected into their reproductive organs and vegetative tissues. CTOMT enzyme activity was mostly concentrated in the petal tissue of both male and female flowers with minimal activity in the calyx, styles and stamens and minimal enzyme activity was found in non-floral tissues (Fig. 5b). It should be noted that only flower tissues are known to produce substantial amounts of guaiacol and veratrole, so the absence of significant CTOMT activity in non-floral tissues was therefore not surprising. a
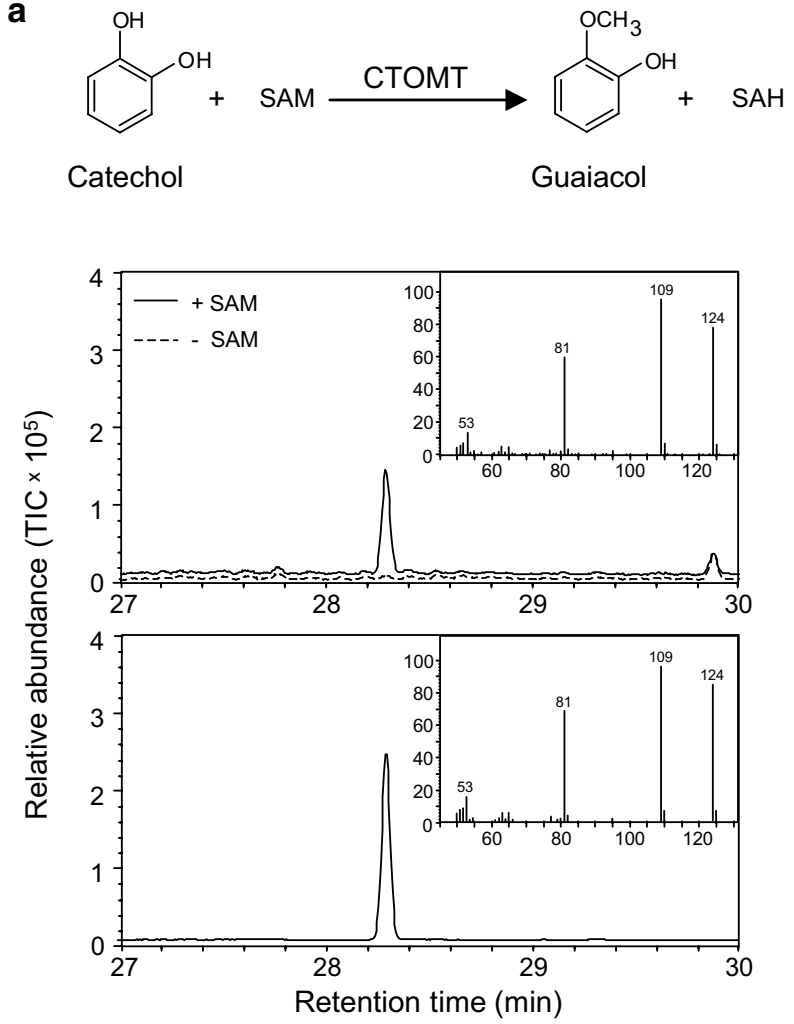

b
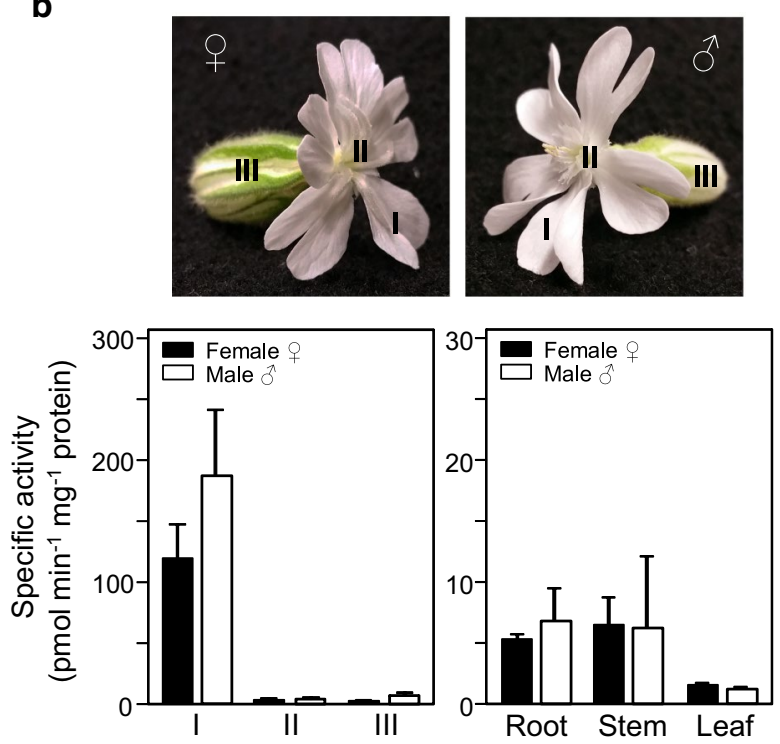

Fig. 5 Catechol- $O$-methyltransferase enzyme activity in the flowers of Silene latifolia. a Evidence for the enzymatic conversion of catechol to guaiacol by an $S$-adenosyl-L-methionine (SAM)-dependent catechol- $O$-methyltransferase (CTMOT). Desalted crude flower extracts were assayed for CTOMT enzyme activity with or without SAM and the reaction products were analyzed by GCMS. A single product peak was detected only in assays containing SAM (upper panel) whose mass spectra (inset) matched that of authentic guaiacol standard (lower panel). b Tissue distribution of CTOMT activity. Female and male flowers (upper panel) were dissected into petals (I), styles or stamens (II), and calyces (III), respectively, and enzyme activity was assayed in desalted crude extracts using $1 \mathrm{mM}$ guaiacol and ${ }^{14} \mathrm{C}-\mathrm{SAM}$ (lower panel). Note that CTOMT enzyme activity in vegetative tissues (leaf, stem, and root) is several fold lower in comparison. Specific activity values are the means \pm SD of three independent experiments using tissue pooled from three male or three female plants 


\section{The evolution of floral volatiles in S. Iatifolia}

Since the accidental introduction of $S$. latifolia to North America approximately 200 years ago, there have been a series of phenotypic changes within this population (Blair and Wolfe 2004). One such post-introduction evolutionary change has been the constitution of its floral bouquet, whereby many North American plants do not emit veratrole and/or other volatiles (Dötterl et al. 2005; Dötterl and Jürgens 2005; Akhtar and Pichersky 2013). Throughout the course of our analysis, we identified several plants (both male and female) which did not emit guaiacol and veratrole among this North American population (Fig. 6a). We predicted that a lack of CTMOT activity in these plants could account for this floral volatile phenotype, so enzymatic assays (as outlined above) were therefore conducted with emitters and non-emitters of both guaiacol and veratrole. Crude protein extracts from emitters of guaiacol and veratrole that were supplied catechol and $\left[{ }^{14} \mathrm{C}\right]-\mathrm{SAM}$ readily produced labeled guaiacol; however, non-emitters completely lacked this CTOMT enzyme activity (Fig. 6b). These results lend genetic support for the role of CTOMT in both guaiacol and veratrole production and also highlight a unique
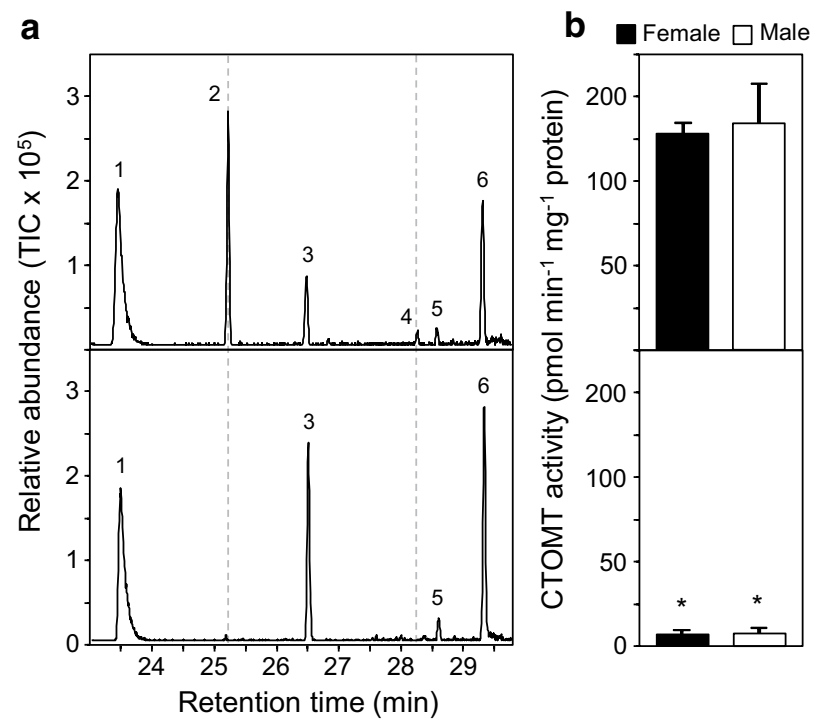

Fig. 6 Veratrole emission depends on the expression of CTOMT. a Representative GC-MS traces of the volatile compounds emitted from flowers that produce veratrole and guaiacol (upper panel) and those that do not (lower panel).The missing veratrole (2) and guaiacol (4) peaks in the lower panel are indicated with dashed lines. The other peaks are indicated by the following numbers: (1) phenylacetaldehyde, (3) methyl salicylate, (5) benzyl alcohol, and (6) phenylethanol. b Total CTOMT enzyme activity in crude flower tissue extracts from veratrole and guaiacol emitters and non-emitters. Data are the mean values \pm SE obtained from three independent extractions of pooled tissue from the corresponding groups. Asterisks (*) indicate statistical significance $(P>0.05)$ resource to further study SA catabolism in S. latifolia, a point of discussion that we return to below.

\section{Discussion}

Evidence is provided in this study for an in planta catabolic pathway for the essential plant hormone, salicylic acid (SA). Using flowers from $S$. latifolia, a series of stable isotope feeding and isotope trapping experiments were employed to demonstrate that SA can be converted into catechol, a widespread phenolic compound that appears to accumulate in several species throughout the plant kingdom-examples of catechol accumulation have been noted in several monocots and among members of the core eudicots (including individuals from the Rosids, Asterids, and Caryophyllales), as well as in some basal angiosperms (Tomazsewski 1960; Vázqueza et al. 1968; Yoshi-Stark et al. 2003; Yang et al. 2004; Morse et al. 2007; Mageroy et al. 2012). If the origin of catechol within these plants is also due, even in part, to SA catabolism, it raises two important questions: First, how is SA converted into catechol, and second, how do plants dispose of catechol?

The conversion of SA into catechol was first reported in P. putida, and subsequently in other related bacteria as well as in fungi (Yamamoto et al. 1965; Rabe et al. 2013; Ambrose et al. 2015; Rocheleau et al. 2019). In these organisms, SA is oxidatively decarboxylated directly into catechol by enzymes that belong to the flavin-dependent monooxygenase superfamily. The most studied and prototypical member from bacteria, NahG, utilizes FAD and NADPH as cofactors to regiospecifically replace the carboxyl group on SA with a hydroxyl moiety on the ortho position relative to the phenol group (Ambrose et al. 2015; Costa et al. 2019). Results from our stable isotope feeding experiments indeed support the notion of an analogous enzymatic conversion of SA directly into catechol, in planta. To date, however, an orthologous activity has yet to be ascribed to any single gene product in plants. Perhaps complicating the search for a bona fide FAD-dependent 'salicylate-1-monooxygenase' in plants is that the flavincontaining monooxygenase (FMO) family is large; Arabidopsis is predicted to have at least 29 FMO members (Schlaich 2007). Moreover, these enzymes are known to oxidize a diverse range of substrates, and while some plant FMOs possess narrow substrate specificity, it is unclear whether a strict relationship between sequence similarity and substrate preference exists for this family of enzymes (Hansen et al. 2007; Schlaich 2007; Dai et al. 2013; Huijbers et al. 2014; Kong et al. 2016; Hartmann et al. 2018). In addition, some members of the FMO superfamily are known to require a unique suite of partner proteins during the reduction step of their flavin cofactor (Ellis 2010). That 
being said, it cannot be ruled out that plants may utilize a different class of oxygenase-type enzymes altogether to catalyze the regiospecific decarboxylation and orthohydroxylation of SA into catechol.

In bacteria and fungi, catechol is a central intermediate in the ortho- and meta-cleavage pathways which operate to degrade a wide variety of aromatic substrates (including SA) into simple Krebs cycle constituents (Hamzah and Al-Baharna 1994; Cao et al. 2008; Wadke et al. 2016). For example, among many Pseudomonas sp., catechol is cleaved at the ortho position by catechol 1,2-dioxygenase to produce succinate and acetyl-CoA or by catechol 2,3-dioxygenase at the meta position to yield acetaldehyde and pyruvate (Loh and Chua 2002; Cao et al. 2008). Interestingly, SA is not the only phytohormone that can be used as a carbon source by these species and other related rhizobacterium-many can also convert the widespread plant hormone, indole-3-acetic acid (IAA), into catechol which is then processed through the same ortho- and meta-cleavage pathways (Donoso et al. 2016). Whether a similar avenue of aromatic catabolism has co-evolved within higher plants is not yet known. Nevertheless, there is some indication that the meta-cleavage pathway may be present in certain species of algae (Semple and Cain 1996) and it is well established that several plants have the capacity to convert simple phenolic compounds into $\mathrm{CO}_{2}$ (Tateoka 1970; Ellis 1971, 1977; Prasad and Ellis 1978), thereby tempting further inquiry into aromatic catabolism in higher plants.

It is generally thought that the active pools of most phytohormones, such as SA, are regulated by enzymatically modifying the parent molecule into storage forms by way of methylation, hydroxylation, glycosylation, or by other means (Seo et al. 2001; Ljung et al. 2002; Jin et al. 2013). Our data offer a new perspective, in that plants, such as S. latifolia, may possess a way of repurposing SA (and perhaps other aromatic metabolites) via a catabolic network that involves catechol as a central intermediate. In the case of $S$. latifolia, SA appears to be converted into catechol, which is then funneled into the synthesis of two potent pollinator attractants, namely guaiacol and veratrole. In tomato fruit, guaiacol synthesis from catechol also appears to have evolved as an important flavor-associated volatile that might influence the efficiency of seed dispersal (Mageroy et al. 2012). But what about plants that do not synthesize guaiacol or veratrole? The North American population of S. latifolia offers a tractable system to explore such catabolism, as this population appears to lack the ability to release SA catabolites in the form of volatile compounds (Akhtar and Pichersky 2013). Moving forward, an approach that combines the genetics of this unique population of plants with stable isotope labeling may serve as a useful tool to elucidate novel pathways in aromatic compound catabolism that have evolved in plants, akin to their bacterial ancestors.
Author contribution statement TAA conceived and designed the research. KVG, TF and TAA conducted the experiments. KVG and TAA analyzed the data and wrote the manuscript. All authors read and approved the manuscript.

Acknowledgements We thank Dr. Lynda Delph (Indiana University) for providing seeds of Silene latifolia and Tannis Slimmon and Michael Mucci for help with plant growth maintenance. We also thank Drs. Dyanne Brewer and Armen Charchoglyan for their advice and expertise on gas chromatography and mass spectrometry. This work was supported by a Natural Sciences and Engineering Research Council of Canada (NSERC) Discovery Grant to T.A. Akhtar. This project was supported by Natural Sciences and Engineering Research Council of Canada grant no. RGPIN-2014-05628.

Open Access This article is licensed under a Creative Commons Attribution 4.0 International License, which permits use, sharing, adaptation, distribution and reproduction in any medium or format, as long as you give appropriate credit to the original author(s) and the source, provide a link to the Creative Commons licence, and indicate if changes were made. The images or other third party material in this article are included in the article's Creative Commons licence, unless indicated otherwise in a credit line to the material. If material is not included in the article's Creative Commons licence and your intended use is not permitted by statutory regulation or exceeds the permitted use, you will need to obtain permission directly from the copyright holder. To view a copy of this licence, visit http://creativecommons.org/licenses/by/4.0/.

\section{References}

Akhtar TA, Pichersky E (2013) Veratrole biosynthesis in white campion. Plant Physiol 162:52-62

Ambrose KV, Tian Z, Wang Y, Smith J, Zylstra G, Huang B, Belanger FC (2015) Functional characterization of salicylate hydroxylase form the fungal endophyte Epichloe festucae. Sci Rep 5:1-12

Attaran B, Zeler TE, Griebel T, Zeler J (2009) Methyl salicylate production and jasmonate signaling are not essential for systemic acquired resistance in Arabidopsis. Plant Cell 21:954-971

Bartsch M, Bednarek P, Vivancos PD, Schneider B, von RoepenackLahaye E, Foyer CH, Kombrink E, Scheel D, Parker JE (2010) Accumulation of isochorismate-derived 2,3-dihydroxybenzoic 3-O- $\beta$-D-xyloside in Arabidopsis resistance to pathogens and ageing in leaves. J Biol Chem 33:25654-25665

Blair AC, Wolfe LM (2004) The evolution of an invasive plant: an experimental study with Silene latifolia. Ecology 85:3035-3042

Bradford MM (1976) A rapid and sensitive method for the quantitation of microgram quantities of protein, utilizing the principle of protein-dye binding. Anal Biochem 72:248-254

Cao B, Geng A, Loh KC (2008) Induction of ortho- and meta-cleavage pathways in Pseudomonas in biodegradation of high benzoate concentration: MS identification of catabolic enzymes. Appl Microbiol Biotechnol 81:99-107

Chen F, D'Auria JC, Tholl D, Ross JR, Gershenzon J, Noel JP, Pichersky E (2003) An Arabidopsis thaliana gene for methylsalicylate biosynthesis, identified by a biochemical genomics approach, has a role in defense. Plant J 36:577-588

Chen Z, Zhen Z, Huang J, Lai Z, Fan B (2009) Biosynthesis of salicylic acid in plants. Plant Signal Behav 4:493-496

Chong J, Pierrel MA, Atanassova R, Werck-Reichhart D, Fritig B, Saindrenan P (2001) Free and conjugated benzoic acid in tobacco 
plants and cell cultures. Induced accumulation upon elicitation of defense responses and role as salicylic acid precursors. Plant Physiol 125:318-328

Costa DMA, Gómez SV, de Araúja SS, Pereira MS, Alves RB, Favaro DC, Hengge AC, Nagem RAP, Brandão TAS (2019) Catalytic mechanism for the conversion of salicylate into catechol by the flavin-dependent monooxygenase salicylate hydroxylase. Int $\mathbf{J}$ Biol Macromol 129:588-600

Dai X, Mashiguchi K, Chen Q, Kasahara H, Kamiya Y, Ojha S, DuBois J, Ballou D, Zhao Y (2013) The biochemical mechanism of auxin biosynthesis by an Arabidopsis YUCCA flavin-containing monooxygenase. J Biol Chem 288:1448-1457

Dean JV, Delaney SP (2008) Metabolism of salicylic acid in wild-type, ugt $74 f 1$ and ugt74f2 glucosyltransferase mutants of Arabidopsis thaliana. Phyisol Plant 132:417-425

Dean JV, Mohammed LA, Fitzpatrick T (2005) The formation, vacuolar localization, and tonoplast transport of salicylic acid glucose conjugates in tobacco cell suspension cultures. Planta 221:287-296

Delaney TP, Uknes S, Vernooij B, Friedrich L, Weymann K, Negrotto D, Gaffney T, Gut-Rella M, Kessmann H, Ward E, Ryals J (1994) A central role of salicylic acid in plant disease resistance. Science 266:1247-1250

Dempsey DMA, Vlot AC, Wildermuth MC, Klessig DF (2011) Salicylic acid biosynthesis and metabolism. Arabidopsis Book. https://doi.org/10.1199/tab.0156

Donoso R, Leiva-Novoa P, Zúñiga A, Timmermann T, RecabarrenGajardo G, González B (2016) Biochemical and genetic bases of indole-3-acetic acid (auxin phytohormone) degradation by the plant-growth-promoting rhizobacterium Paraburkholderia phytofirmans PsJN. Appl Environ Microbiol 83:e01991-e2016. https://doi.org/10.1128/AEM.01991-16

Dötterl S, Jürgens A (2005) Spatial fragrance patterns in flowers of Silene latifolia: lilac compounds as olfactory nectar guides? Plant Syst Evol 255:99-109

Dötterl S, Wolfe LM, Jürgens A (2005) Qualitative and quantitative analyses of flower scent in Silene latifolia. Phytochemistry 66:203-213

Dötterl S, Jürgens A, Seifert K, Laube T, Weißbecker B, Schütz S (2006) Nursery pollination by a moth in Silene latifolia: the role of odours in eliciting antennal and behavioural responses. New Phytol 169:707-718

El-Basyouni S, Chen D, Ibrahim RK, Neish AC, Towers GHN (1964) The biosynthesis of hydroxybenzoic acids in higher plants. Phytochemistry 3:485-492

Ellis BE (1971) A survey of catechol ring-cleavage by sterile plant tissue cultures. FEBS Lett 18:228-230

Ellis BE (1977) Degradation of phenolic compounds by fresh-water algae. Plant Sci Lett 8:213-216

Ellis HR (2010) The FMN-dependent two-component monooxygenase systems. Arch Biochem Biophys 497:1-12

Gaffney T, Friedrich L, Vernooij B, Negrotto D, Nye G, Uknes S, Ward E, Kessmann H, Ryals J (1993) Requirement of salicylic acid for the induction of systemic acquired resistance. Science 261:754-756

Gupta AK, Akhtar TA, Widmer A, Pichersky E, Schiestl FP (2012) Identification of white campion (Silene latifolia) guaiacol $O$-methyltransferase involved in the biosynthesis of veratrole, a key volatile for pollinator attraction. BMC Plant Biol 12:158-170

Hamzah RY, Al-Baharna BS (1994) Catechol ring-cleavage in Pseudomonas cepacia: the simultaneous induction of ortho and meta pathways. Appl Microbiol Biotechnol 41:250-256

Hansen BG, Kliebenstein DJ, Halkier BA (2007) Identification of a flavin-monooxygenase as the S-oxygenating enzyme in aliphatic glucosinolate biosynthesis in Arabidopsis. Plant J 50:902-910
Hartmann M, Zeier T, Bernsdorff F, Reichel-Deland V, Kim D, Hohmann M, Scholten N, Schuck S, Bräutigam A, Hölzel T, Ganter C, Zeier J (2018) Flavin monooxygenase-generated N-hydroxypipecolic acid is a critical element of plant systemic immunity. Cell 173:456-469

Helmerhorst E, Stokes GB (1980) Microcentrifuge desalting: a rapid, quantitative method for desalting small amounts of protein. Anal Biochem 104:130-135

Huijbers MME, Montersino S, Westphal AH, Tischler D, van Berkel WJH (2014) Flavin dependent monooxygenases. Arch Biochem Biophys 544:2-17

Jagadeeswaran G, Raina S, Acharya BR, Maqbool SB, Mosher SL, Appel HM, Schultz JC, Klessig DF, Raina R (2007) Arabidopsis GH3-LIKE DEFENSE GENE 1 is required for accumulation of salicylic acid, activation of defense responses and resistance to Pseudomonas syringae. Plant J 51:234-246

Jarvis AP, Schaaf O, Oldham NJ (2000) 3-Hydroxy-3-phenylpropanic acid is an intermediate in the biosynthesis of benzoic acid and salicylic acid but benzaldehyde is not. Planta 212:119-126

Jin SH, Ma XM, Han P, Wang B, Sun YG, Zhang GZ, Li YJ, Hou BK (2013) UGT74D1 is a novel auxin glycosyltransferase from Arabidopsis thaliana. PLoS ONE 8:e61705. https://doi.org/10.1371/ journal.pone.061705

Jürgens A, Witt T, Gottsberger G (2002) Flower scent composition in night-flowering Silene species (Caryophyllaceae). Biochem Syst Ecol 30:383-397

Klessig DF, Choi HW, Dempsey DMA (2018) Systemic acquired resistance and salicylic acid: past, present and future. Mol Plant MIcrobe In 31:871-888

Knudsen JT, Eriksson R, Gershenzon J, Ståhl B (2006) Diversity and distribution of floral scent. Bot Rev 72:1-120

Koeduka T, Kajiyama M, Furuta T, Suzuki H, Tsuge T, Matsui K (2016) Characterization of an $O$-methlytransferase specific to guaiacol-type benzenoids from the flowers of loquat (Eriobotrya japonical). J Biosci Bioeng 122:679-684

Kong W, Li J, Cang W, Xu R, Wang Y, Ji W (2016) Two novel flavincontaining monooxygenases involved in biosynthesis of aliphatic gluosinolates. Front Plant Sci 7:1292. https://doi.org/10.3389/ fpls.2016.01292

Lee MW, Lu H, Jung HW, Greenberg JT (2007) A key role for the Arabidopsis WIN3 protein in disease resistance triggered by Pseudomonas syringae that secrete AvrRpt2. Mol Plant Microbe 20:1192-1200

Ljung K, Hull AK, Kowalczyk M, Marchant A, Celenza J, Cohen JD, Sandberg G (2002) Biosynthesis, conjugation, catabolism and homeostasis of indole-3-acetic acid in Arabidopsis thaliana. Plant Mol Biol 50:309-332

Loh KC, Chua SS (2002) Ortho pathway of benzoate degradation in Pseudomonas putida: induction of meta pathway at high substrate concentrations. Enzyme Microb Tech 30:6220-6626

Mageroy MH, Tieman DM, Floystad A, Taylor MG, Klee HJ (2012) A Solanum lycopersicum catechol- $O$-methyltransferase involved in synthesis of the flavor molecule guaiacol. Plant J 69:1043-1051

Morse AM, Tschaplinski TJ, Dervinis C, Pijut PM, Schmelz EA, Day W, Davis JM (2007) Salicylate and catechol levels are maintained in $n a h G$ transgenic poplar. Phytochemistry 68:2043-2052

Nawrath C, Heck S, Parinthawong N, Métraux JP (2002) EDS5, an essential component of salicylic acid-dependent signaling for disease resistance in Arabidopsis, is a member of the MATE transporter family. Plant Cell 14:275-286

Nobuta K, Okrent RA, Stoutemyer MS, Rodibaugh N, Kempema L, Wildermuth MC, Innes RW (2007) The GH3 acyl adenylase family member PBS3 regulates salicylic acid-dependent defense responses in Arabidopsis. Plant Physiol 144:1144-1156 
Park SW, Kaimoyo E, Kumar D, Mosher S, Klessig DF (2008) Methyl salicylate is a critical mobile signal for plant systemic acquired resistance. Science 318:113-116

Pichersky E, Gershenzon J (2002) The formation and function of plant volatiles: perfumes for pollinator attraction and defense. Curr Opin Plant Biol 5:237-243

Prasad S, Ellis BE (1978) In vivo characterization of catechol ringcleavage in cell cultures of Glycine max. Phytochemistry 17:187-190

Rabe F, Ajami-Rasidi Z, Doehlemann G, Kahmann R, Djamei A (2013) Degradation of the plant defence hormone salicylic acid by the biotrophic fungus Ustilago maydis. Mol Microbiol 89:179-188

Rekhter D, Lüdke D, Ding Y, Feussner K, Zienkiewicz K, Lipka V, Wiermer M, Zhang Y, Feussner I (2019) Isochorismate-derived biosynthesis of the plant stress hormone salicylic acid. Science 365:498-502

Ribnicky DM, Shulaev V, Raskin I (1998) Intermediates of salicylic acid biosynthesis in tobacco. Plant Physiol 118:565-572

Rivas-San Vicente M, Plasencia J (2011) Salicylic acid beyond defence: its role in plant growth and development. J Exp Bot 62:3321-3338

Rocheleau H, Al-harthi R, Ouellet T (2019) Degradation of salicylic acid by Fusarium graminearum. Fungal Biol 123:77-86

Ross JR, Nam KH, D’Auria JC, Pichersky E (1999) S-Adenosyl-Lmethionine:salicylic acid carboxyl methyltransferase, an enzyme involved in floral scent production and plant defense, represents a new class of plant methyltransferases. Arch Biochem Biophys 367:9-16

Schlaiach NL (2007) Flavin-containing monooxygenases in plants: looking beyond detox. Trends Plant Sci 12:218-412

Seguel A, Jelenska J, Herrera-Vásquez A, Marr SK, Joyce MB, Gagesch KR, Shakoor N, Jiang SC, Fonseca A, Wildermuth MC, Greenberg JT, Holuigue L (2018) PROHIBITIN3 forms complexes with Isochorismate Synthase1 to regulate stress-induced salicylic acid biosynthesis in Arabidopsis. Plant Physiol 176:2515-2531

Semple KT, Cain RB (1996) Biodegradation of phenols by the alga Ochromonas danica. App Environ Microbiol 62:1265-1273

Seo S, Ishizuka K, Ohashi Y (1995) Induction of salicylic acid $\beta$-glucosidase in tobacco leaves by exogenous salicylic acid. Plant Cell Physiol 36:447-453

Seo HS, Song JT, Cheong JJ, Lee YH, Lee YW, Hwang I, Lee JS, Choi YD (2001) Jasmonic acid carboxyl methyltransferase: a key enzyme for jasmonate-regulated plant responses. Proc Natl Acad Sci USA 98:4788-4793

Serrano M, Wang B, Aryal B, Garcion C, Abou-Mansour E, Heck S, Geisler M, Mauch F, Nawrath C, Métraux JP (2013) Export of salicylic acid from the chloroplast requires the multidrug and toxin extrusion-like transporter EDS5. Plant Physiol 162:1815-1821

Song JT, Koo YJ, Seo HS, Kim MC, Choi YD, Kim JH (2008) Overexpression of AtSGT1, an Arabidopsis salicylic acid glucosyltransferase, leads to increased susceptibility to Pseudomonas syringae. Phytochemistry 69:1128-1134

Strawn MA, Marr SK, Inoue K, Inada N, Zubieta C, Wildermuth MC (2007) Arabidopsis isochorismate synthase functional in pathogen-induced salicylate biosynthesis exhibits properties consistent with a role in diverse stress responses. J Biol Chem 282:5919-5933

Tateoka TN (1970) Studies on the catabolic pathway of protocatechuic acid in mung bean seedlings. Bot Mag 83:49-59

Tomazsewski W (1960) The occurrence of p-hydroxybenzoic acid and other simple phenols in vascular plants. Bull Acad Polonaise Sci $8: 61-65$
Torrens-Spence MP, Bobokalonova A, Carballo V, Glinkerman CM, Pluskal T, Shen A, Weng JK (2019) PBS3 and EPS1 complete salicylic acid biosynthesis from isochorismate in Arabidopsis. Mol Plant 12:1577-1586

Towers GHN, Tse A, Maass WSG (1966) Phenolic acids and phenolic glycosides of Gaultheria species. Phytochemistry 5:677-681

van Wees SCM, Glazebrook J (2003) Loss of non-host resistance of Arabidopsis NahG to Pseudomonas syringae pv. phaseolicola is due to degradation products of salicylic acid. Plant J 33:733-742

Vázqueza A, Méndeza J, Gestoa MDV, Seoanea E, Vieitez E (1968) Growth substances isolated from woody cuttings of Salix viminalis L. and Ficus carica L. Phytochemistry 7:161-167

Vlot AC, Dempsey DMA, Klessig DF (2009) Salicylic acid, a multifaceted hormone to combat disease. Annu Rev Phytopathol 47:177-206

Wadke N, Kandasam D, Vogel H, Lah L, Wingfield BD, Paetz C, Wright LP, Gershenzon J, Hammerbacher A (2016) The blackbeetle-associated fungus, Endoconidiophora polonica, utilizes the phenolic defense compounds of its host as a carbon source. Plant Physiol 171:914-931

Wildermuth MC (2006) Variations on a theme: synthesis and modification of plant benzoic acids. Curr Opin Plant Biol 9:288-296

Wildermuth MC, Dewdney J, Wu G, Ausubel FM (2001) Isochorismate synthase is required to synthesize salicylic acid for plant defence. Nature 414:562-565

Yalpani N, León J, Lawton MA, Raskin I (1993) Pathway of salicylic acid biosynthesis in healthy and virus-inoculated tobacco. Plant Physiol 103:315-321

Yamamoto S, Katagiri M, Maeno H, Hayaishi O (1965) Salicylate hydroxylase, a monooxygenase requiring flavin adenine dinucleotide. J Biol Chem 240:3408-3413

Yang Y, Qi M, Mei C (2004) Endogenous salicylic acid protects rice plants form oxidative damage caused by aging as well as biotic and abiotic stress. Plant J 40:909-919

Yoshi-Stark Y, Hseieh YP, Suzuki T (2003) Distribution of flavonoids and related compounds from seaweeds in Japan. J Tokio Univ Fish 89:1-6

Zhang Y, Li X (2019) Salicylic acid: biosynthesis, perception, and contribution to plant immunity. Curr Opin Plant Biol 50:29-36

Zhang Y, Xu S, Ding P, Wang D, Cheng YT, He J, Gao M, Xu F, Li Y, Zhu Z, Li X, Zhang Y (2010) Control of salicylic acid synthesis and systemic acquired resistance by two members of a plant specific family of transcription factors. Proc Natl Acad Sci USA 107:18220-18225

Zhang K, Halittschke R, Yin C, Liu CJ, Gan SS (2013) Salicylic acid 3-hydroxylase regulates Arabidopsis leaf longevity by mediating salicylic acid catabolism. Proc Natl Acad Sci USA 110:14807-14812

Zhang Y, Zhao L, Li Y, Wang J, Guo R, Gan S, Liu CJ, Zhang K (2017) S5H/DMR6 encodes a salicylic acid 5-hydroxylase that fine-tunes salicylic acid homeostasis. Plant Phyisol 175:1082-1093

Zheng Z, Qualley A, Fan B, Dudareva N, Chen Z (2009) An important role of a BAHD acyl transferase-like protein in plant innate immunity. Plant J 57:1040-1053

Publisher's Note Springer Nature remains neutral with regard to jurisdictional claims in published maps and institutional affiliations. 